Carcinoma of the bronchus has not been described as producing antibodies to other substances, and there is no evidence of this in the present case.

The failure of serum taken after the tumour was irradiated to inhibit iron utilization suggests that the tumour was the site of production of the abnormal substance. The possible effect of storage on this serum cannot, however, be disregarded. The failure of the anaemia to recover after treatment may be due to the dose of radiation received.

\section{Summary}

A case of carcinoma of the bronchus presenting with pure red-cell aplasia is described. A humoral factor was present in the patient's serum which inhibited iron utilization in rabbits. This factor disappeared after irradiation of the tumour, but recovery of the anaemia did not occur.
We wish to thank Professor H. Scarborough and Dr. A. H. James for permission to publish details of this case.

\section{REFERENCES}

Andersen, S. B., and Ladefoged, J. (1963). Acta haemat. (Basel), 30, 319. Gordon, R. R., and Varadi, S. (1962). Lancet, 1, 296.

Greenberg, E., Divertie, M. B., and Woolner, L. B. (1964). Amer. F. Med., 36, 106.

Jacobs, E. M., Hutter, R. V. P., Pool, J. L., and Ley, A. B. (1959). Cancer (Philad.), 12, 47.

Jahsman, D. P., Monto, R. W., and Rebuck, J. W. (1962). Amer. 7. clin. Path., 38, 152.

Parry, E. H. O., Kilpatrick, G. S., and Hardisty, R. M. (1959). Brit. med. \}., 1, 1154 .

Ramos, A. J., and Loeb, V. (1956). F. Amer. med. Ass., 160, 1317.

Schmid, J. R., Kiely, J. M., Pease, G. L., and Hargraves, M. M. (1963). Acta haemat. (Basel), 30, 255.

Schooley, J. C., and Garcia, J. F. (1962). Proc. Soc. exp. Biol. (N.Y.), 109,325 .

\title{
Simple Operation for the Overlapping Fifth Toe
}

\author{
STANLEY HULMAN,* M.B., CH.B.
}

Brit. med. F., 1964, 2, 1506-1507

An overlapping fifth toe (Fig. 1) is sometimes the cause of considerable discomfort, but often advice is sought for purely cosmetic reasons. There is no tendency to spontaneous improvement, and when uncorrected the fifth toe often becomes painful owing to pressure from the shoe.

Various methods of treatment have been described. Many authors still suggest the use of strapping applied to hold the toe in the corrected position, but this is generally regarded as of little or no value. Some writers-for example, Jones and Lovett (1929) and Perkins (1961)-suggested that amputation of the toe is advisable. This may be so in the middle-aged or elderly, but amputation ought not to be advised in the young. Amputa-
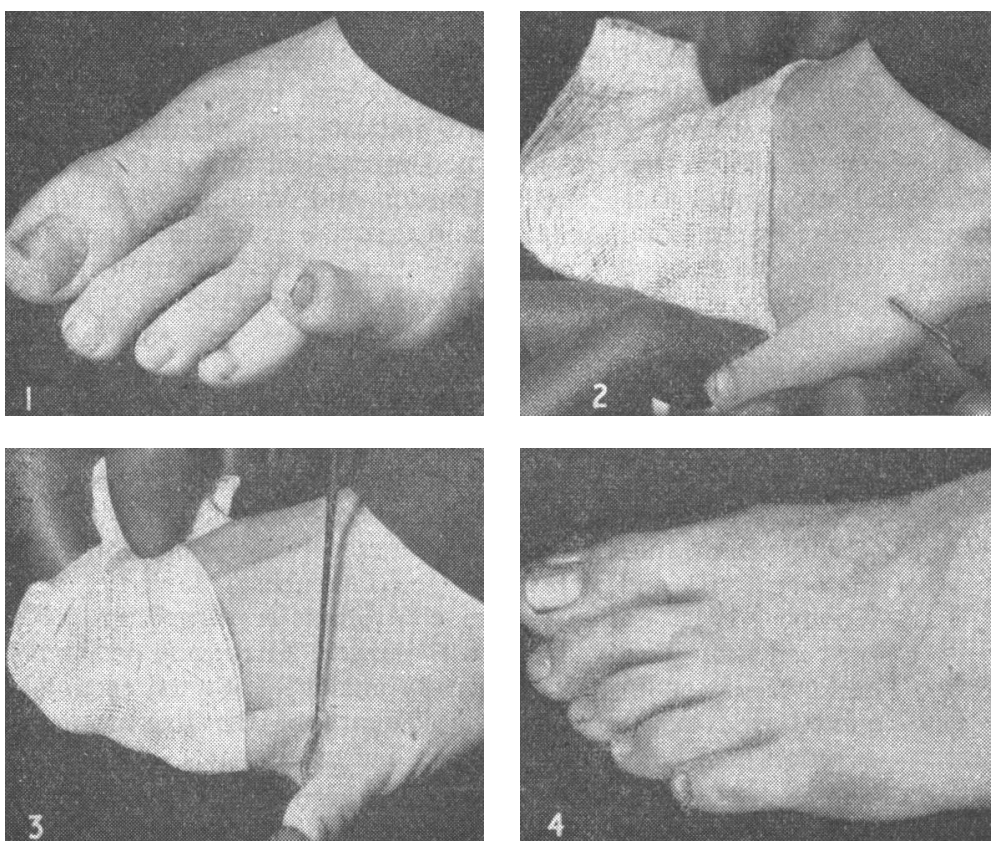

Fig. 1.-Varus fifth toe in boy aged 12. FIG. 2.- Tenotomy and capsulotomy. FIG. 3.-Approximation of skin edges. FIG. 4.-Fourteen months after operation tion predisposes to tenderness over the head of the fifth metatarsal (Stamm, 1948), and is psychologically undesirable in young people.

All the methods of operative treatment that have been described have serious limitations. One of the simplest procedures is the V-Y plastic elongation of the dorsal skin (Stamm, 1948 ; Wilson, 1953), but this sometimes leads to an ugly and keloidal scar or recurrence (Scrase, 1953).

Colonna (1950) favoured the method in which the extensor tendon is divided at its insertion and transplanted into the shaft of the fifth metatarsal, followed by division and stretching of the contracted dorsal capsule. The toe is then held for a few weeks in plaster. The illustration in his book shows a large operative scar which may tend to become keloidal and which in any event is very ugly.

McFarland (1950) used the method of " syndactylization" in which a fillet of skin is excised from the adjacent surfaces of the fourth and fifth toes. The base of the proximal phalanx of the fifth toe is removed and the adjacent edges of the raw areas are sutured together. The fifth toe is thus held permanently secured to the fourth.

The method of Lapidus (1942), in which the divided extensor tendon is threaded round the proximal part of the toe and attached to the abductor digiti minimi tendon, necessitates two dorsal incisions. It is a quite extensive operation, and in some instances the toe will later deviate into valgus.

\section{Method of Treatment}

Because of the limitations to the operations described, a relatively simple procedure has been used for some years which seems to be satisfactory. The operation consists of a subcutaneous tenotomy of the

* From the Department of Orthopaedics, St. James's Hospital, Leeds. 
extensor tendon and incision of the dorsal and medial aspects of the capsule of the metatarsophalangeal joint, using a fine tenotome (Fig. 2). A wide ellipse of skin is then excised from the web between the fourth and fifth toes, the long axis of the ellipse being directed in an antero-medial to postero-lateral direction. The skin is then sutured, using Gillies's hooks to approximate the edges (Fig. 3). A small piece of gauze is placed over the wound and the fifth toe is held in the corrected position with 1 -in. (6-mm.) strapping. Wool and a crêpe bandage are placed over the toe for a few days. An ordinary shoe may be worn in a week or 10 days. The sutures are retained for about 14 days. Two details of technique are to be mentioned: firstly, the capsulotomy is made easier by applying firm longitudinal traction to the toe; and, secondly, as the sutures are a little difficult to place because of the confined space, a Denis Brown $\frac{5}{8}$ circle cleft-palate needle is helpful. Fig. 4 shows the shape of the toe 14 months after operation.

The results of 35 operations (five bilateral) in 30 patients have been reviewed ; 23 patients were females and 7 were males. The reviews took place between six months and seven years after operation. Twenty-seven of the patients were aged 9-18 years, the number being fairly evenly distributed. This group accounted for 32 operations, and the results were all satisfactory both in appearance and in absence of symptoms. In two patients, a woman of 42 and a man of 35 , discomfort persisted in spite of an improved position of the toe. The youngest patient was a child of 11 months at the time of operation, and when reviewed three and a half years later the result was quite satisfactory; it is now thought, however, that there is no advantage in operating on so young a child.

\section{Summary}

Methods of correcting the varus deformity of the fifth toe to be found in the literature are mentioned. All have disadvantages. A method of treatment is described in which bone is not excised and the scar is not visible. This consists of a subcutaneous tenotomy of the extensor tendon, capsulotomy of the metatarsophalangeal joint, and excision of an oblique ellipse of skin from the web between the fourth and fifth toes, the defect then being sutured.

In a series of 35 operations good results were obtained in 33, and the operation is suitable as an out-patient procedure.

I am indebted to Mr. G. Hyman, Mr. R. Broomhead, Mr. J. M. Fitton, and Mr. H. N. Burwell for allowing me to operate on patients under their care ; to Mr. A. B. Pain for his encouragement to publish this paper; and to Mr. J. M. P. Clark for much helpful advice. The Department of Medical Photography at St. James's Hospital, Leeds, provided the photographs.

\section{REFERENCES}

Colonna, P. C. (1950). Regional Orthopaedic Surgery, p. 492. Saunders, Philadelphia.

Jones, R., and Lovett, R. W. (1929). Orthopaedic Surgery, 2nd ed., p. 666. Oxford University Press, London.

Lapidus, P. W. (1942). 3. Bone fi Surg., 24, 555.

Lapidus, P. B. (1950). In Modern Trends in Orthopaedics, edited by Sir Harry Platt, p. 107. Butterworth, London.

Perkins, G. (1961). Orthopaedics, p. 662. Athlone Press, London.

Scrane, W. H. (1953). Lancet, 2, 974.

Stamm, T. T. (1948). British Surgical Practice, 4, 161. Butterworth, London.

Wilson, J. N. (1953). Brit. F. Surg., 41, 133.

\section{Preliminary Communications}

\section{Angiotensin and Reno-portal Anastomosis}

Brit. med.F., 1964, 2, 1507-1508

It was generally accepted (Levy and Blalock, 1938 ; Child and Glenn, 1938 ; Maluf, 1956 ; Kubicek and Thal, 1963) that, in the experimental animal, complete diversion of the renal effluent blood into the portal vein could not prevent the hypertension produced by renal-artery constriction. Recently Japanese workers have reported both prevention and cure of experimental hypertension due to renal-artery constriction and to glomerulonephritis by reno-portal anastomosis in dogs (Ito et al., 1961 ; Aoki, 1962 ; Sakamoto, 1963). They anastomosed the right renal vein to the portal vein or superior mesenteric vein (the left kidney was removed prior to the experiment) and attributed their success, compared with the failure of previous workers, to differences in surgical technique whereby the formation of capsular anastomoses allowing renal effluent blood to by-pass the liver was discouraged. Alternatively it might be that the conditions of their experiments required the liver to inactivate a smaller quantity of a substance provoking hypertension than in the experiments of earlier workers.

Prevention of hypertension might be due either to inactivation by the liver of renin and/or angiotensin in the renal effluent blood or to liver dysfunction induced by the reno-portal anastomosis with subsequent failure to produce angiotensinogen. Sakamoto (1963) found no evidence of liver dysfunction in dogs with a reno-portal anastomosis. He demonstrated renin in the renal veins of dogs with renal hypertension but not in the hepatic veins of such dogs after reno-portal anastomosis.
The present study was made to elicit further the mechanism of the relief of renal hypertension by reno-portal anastomosis by establishing the ability of the liver to inactivate angiotensin.

\section{METHODS}

Four healthy normotensive mongrel dogs were anaesthetized with halothane after induction with hydroxydione (Presuren). Barbiturate anaesthetic agents were avoided because preliminary experiments showed that thiopentone and pentobarbitone modify the effect of angiotensin. After laparotomy a polythene catheter was inserted into the splenic vein. The abdomen was closed and further catheters were inserted into the abdominal aorta via a femoral artery and into one or other femoral vein. Systemic blood-pressure was measured via the aortic catheter with a Statham P23G strain-gauge and recorded on a Sanborn direct-writing instrument. The animal was allowed to settle to a steady basal state before infusion of angiotensin (asp ${ }^{1}-\beta$ amide-val ${ }^{5}$ octapeptide angiotensin ; Hypertensin-Ciba).

Angiotensin was infused alternately into the systemic circulation via the femoral vein catheter and into the portal circulation via the splenic vein catheter. Each infusion was made at a constant rate and continued until a steady state was achieved before any change in systemic blood-pressure was recorded. The blood-pressure was allowed to fall to the basal level between infusions. Thus dose-response curves were obtained comparing the effect of portal and of systemic angiotensin on systemic blood-pressure.

The procedure was repeated on two normotensive adult male patients about to undergo vagotomy and pyloroplasty for chronic duodenal ulceration. Both were otherwise healthy. 